\title{
The Steeple Sign of Croup in an Adult
}

\author{
Masahiro Kashiura, Shunsuke Amagasa and Takashi Moriya
}

Key words: Airway management, croup, influenza A virus, tracheal stenosis

\author{
(Intern Med Advance Publication) \\ (DOI: 10.2169/internalmedicine.9041-21)
}

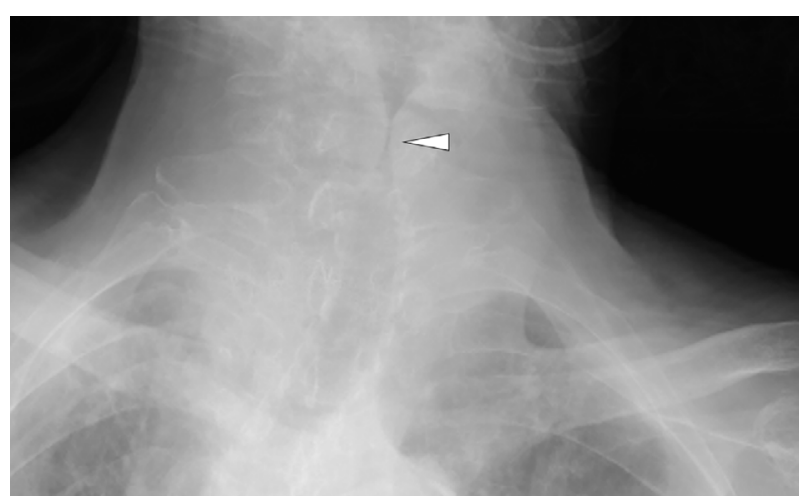

Picture 1.

A 98-year-old woman presented to our emergency department with dyspnea and barking cough. Her respiratory rate was 24 breaths/min, and her oxygen saturation was $90 \%$ on room air. A physical examination revealed stridor on auscultation. Chest radiography demonstrated subglottic stenosis, indicated by the so-called steeple sign (Picture A, arrowhead), as did neck computed tomography (Picture B). A rapid diagnostic test was positive for influenza A. The patient was intubated with a $6.5-\mathrm{mm}$ tracheal tube and received intravenous peramivir $(600 \mathrm{mg} / \mathrm{day})$ for 5 days. She was extubated on the seventh day. Adult croup is a rare, severe condition requiring more aggressive management and longer hospitalization than in children (1). Typical causative microorganisms are parainfluenza virus type 3 , influenza virus, Haemophilus influenzae, Streptococcus, and respiratory syncytial virus (1). Significant subglottic edema is an obvious indication for intubation. A narrow endotracheal tube

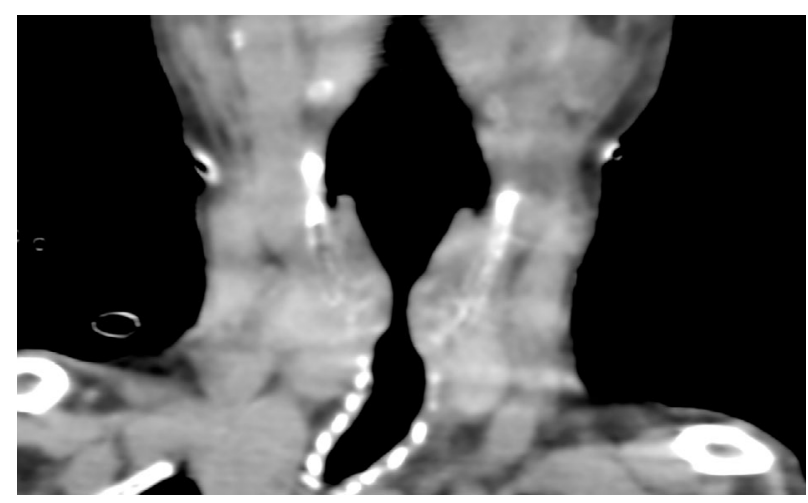

Picture 2.

should be used to overcome subglottic edema and ensure reliable intubation (2).

The authors state that they have no Conflict of Interest (COI).

\section{References}

1. Patel JJ, Kitchin E, Pfeifer K. A Narrowing Diagnosis: A Rare Cause of Adult Croup and Literature Review. Case Rep Crit Care 2017: 9870762, 2017.

2. Woo PC, Young K, Tsang KW, Ooi CG, Peiris M, Yuen K. Adult croup: a rare but more severe condition. Respiration 67: 684-688, 2000.

The Internal Medicine is an Open Access journal distributed under the Creative Commons Attribution-NonCommercial-NoDerivatives 4.0 International License. To view the details of this license, please visit (https://creativecommons.org/licenses/ by-nc-nd/4.0/). 